\title{
Otra escaramuza más en la rivalidad temprana entre Lope y Góngora: el soneto esdrújulo de El caballero del milagro ${ }^{1}$
}

\author{
Santiago Restrepo Ramírez \\ Prolope - Universidad de los Andes \\ srestreporamirez@uniandes.edu.co
}

Recepción: 09/06/2017, Aceptación: 15/07/2017, Publicación: 22/12/2017

\begin{abstract}
Resumen
En este artículo se analiza el sentido cómico y paródico del soneto esdrújulo que declama Luzmán, protagonista de El caballero del milagro, para engañar a sus oponentes Leonato y Camilo. Contra lo que ha defendido alguna crítica, se demuestra que Lope no era ajeno al uso cómico de los versos esdrújulos antes de 1600, pues tenemos al menos tres ejemplos más de estos. Finalmente, teniendo en cuenta el momento histórico en que Lope redacta la comedia (1593), se propone una lectura de esta como una pieza más de la temprana rivalidad entre el dramaturgo madrileño y Luis de Góngora.
\end{abstract}

Palabras clave

Lope de Vega; Góngora; esdrújulo; rivalidad

\begin{abstract}
Another skirmish in the early rivalry between Lope and Góngora: The esdruijulo (proparoxytone) sonnet of $\mathrm{El}$ caballero del milagro

This paper analyzes the comical and parodical sense of the proparoxytone sonnet that Luzmán, a main character in El caballero del milagro, declaims with the purpose of cheating Leonato and Camilo, his opponents. Contrary to what some critiques have argued, it is proved that Lope was not unaware of the comical usage of the verses whose accent falls on the third last syllable before 1600, as there are at least three other examples of
\end{abstract}

1. Este trabajo se beneficia de mi participación en el proyecto «Edición y estudio de treinta y seis comedias de Lope de Vega» (FFI2015-66216-P). 
this kind of versification in his work. Finally, and considering the historical moment when Lope wrote this comedy (1593), a reading, in which the work is seen as another piece in the puzzle of the early rivalry between the madrileño playwright and Luis de Góngora, is proposed.

\section{Keywords}

Lope de Vega; Góngora; proparoxytones; rivalry

Entre noviembre y diciembre de 1593, en Alba de Tormes, Lope redacta El caballero del milagro, según da cuenta el manuscrito Gálvez que se conserva. ${ }^{2} \mathrm{La}$ comedia, de marcado corte picaresco, contiene una pieza poética interesantísima - un soneto esdrújulo, para ser más exacto- no solo a la luz de su función dramática, sino también porque es una pieza más del rompecabezas que es la temprana rivalidad entre nuestro dramaturgo y Luis de Góngora.

A la altura del tercer acto de la comedia se repite una situación que ya se ha vivido en los actos I y II: ${ }^{3}$ Luzmán se encuentra con Leonato y Camilo, que lo reciben enfadados por engaños anteriores con un irónico y despectivo «iAh,

2. Dos fechas refleja el manuscrito: en la portada aparece 30 de noviembre de 1593 , mientras que en la última página, tras concluir el texto, dice 30 de diciembre de 1593. Para la fiabilidad de los datos que aportan los manuscritos copiados por Ignacio de Gálvez en el siglo xviıI, véase el clásico trabajo de Iriso Ariz (1998). Por otra parte, Morley y Bruerton (1968: 238-239) datan la comedia «antes de 1598 (probablemente 1593-1598)».

3. El primer engaño —el cambio de vestidos - se da en el primer acto (vv. 410-444) con su consiguiente descubrimiento por parte del burlado (vv. 923 y ss.); vuelve Luzmán a engañar a Camilo y Leonato en el segundo acto (vv. 1697-1813), revirtiendo el enfado de los soldados espańoles por medio de la adulación, una invitación a cenar y, finalmente, la promesa de una prostituta. 
mi señor don Luzmán / de Toledo y de Mendoza, / señor de potro y carroza!» (vv. 2318-2320); ${ }^{4}$ sin embargo, nuestro incansable e ingenioso pícaro usará sus recursos retóricos para llevar, una vez más, y a pesar de la prevención de sus víctimas, a buen puerto una nueva burla. Y esta nueva burla en la que triunfa la adulación, recurso ya empleado con anterioridad por el pícaro, reduplica o triplica, pues no una ni dos, sino tres veces los engaña, la comicidad de la situación. Luzmán saca de la manga un as y, conocedor del poder de la adulación, le dedica a Leonato un soneto esdrújulo del que, según el protagonista, Apolo le «daba / su armonía y verso junto» (vv. 2324-2325):

LUZMÁN Leonato ilustre, valeroso armífero, contra el fiero cismático y herético y contra el falso alárabe profético, alférez fuerte, capitán belífero, tú que el pendón católico y cristífero has puesto sobre el muro mahomético honrando el suelo vandalino y bético de ingenios y armas fuerte y salutífero, si a Carlos Quinto, príncipe invictísimo, la fama llega de tu esfuerzo bélico, verás de premios un inmenso cúmulo, serás en vida espléndido y riquísimo y en muerte como a mílite evangélico dos mil banderas honrarán el túmulo. (vv. 2350-2363)

Tal composición consigue su fin, que es la reconciliación — solo aparentede Luzmán con los susodichos, quienes quedan encantados: Leonato pregunta en aparte si «¿No es lástima que se ofenda / hombre de esta habilidad», a lo que responde Camilo que "Por ella le haré amistad / y le quiero dar mi hacienda» (vv. 2364-2367); y, como si esto fuera poco, le piden a nuestro poeta «un traslado del soneto» (v. 2369). Luzmán, pues, con su soneto esdrújulo, da vuelta a la situación y la animosidad de sus adversarios se convierte inmediatamente en benevolencia, incluso en generosidad.

Leonato y Camilo son, digamos, los primeros receptores del soneto - los más inmediatos, en todo caso- y lo entienden como serio, épico y de claro

4. Nótese, además, el doble sentido de la expresión «señor de potro», que significa tanto de 'caballo' como del instrumento de tortura y vejación. Cito por la reciente edición de Restrepo y Valdés (2016). 5. Fernández Rodríguez y Valdés (en prensa) reflexionan sobre los sonetos en el teatro lopesco: «El soneto es quizá la única estrofa presente en las comedias que funciona en cuanto género y pieza completa más que como estrofa». Aprovecho la ocasión para agradecerle a los autores que, como siempre, han dado muestras de su generosidad y me han facilitado el texto que pronto verá la luz en papel. Véase, por otra parte, el artículo de Campo Tejedor (2004) sobre los trovadores de repente y su presencia en el teatro, sobre todo entremesil. 
sentido elogioso de sus propios actos. Curiosamente, gran parte de la crítica moderna que lo ha abordado comparte la visión de los soldados españoles de la comedia lopesca: Alatorre (2007: 238 n.), por poner un ejemplo, en su ensayo sobre los esdrújulos lo califica de "otro soneto serio» de Lope. ${ }^{6}$ Ya lo resaltaba Reid (1939: 283, la cursiva es del original), en un estudio clásico, teniendo en cuenta Los locos por el cielo y Los pastores de Belén: «The majority of the passages written by Lope in esdrújulos are in a serious vein and were used merely as metrical ornaments». No obstante, matiza el mismo Reid (1939: 283) que «his genius was too fertile not to see the comic possibilities of the verse» y que "another sonnet [además del que aparece en Los comendadores de Córdoba] inserted with farcical intent is found in El caballero del milagro». Reid, pues, en contraste con Alatorre, entendió de manera muy distinta el soneto citado y remarcó su sentido farsesco. Lectura similar propone Doménech (2007: 154 n.): «Este soneto en rimas esdrújulas es un ejemplo temprano del lenguaje hinchado y retórico propio de los poetas cultos, de los que Góngora habría de ser el más destacado»?

Conviene, a la luz de las discrepancias críticas en cuanto al sentido del soneto, radicales y opuestas, revisarlo junto a sus circunstancias para determinar si estamos ante un texto de carácter serio o cómico. En primer lugar, debemos prestar atención al personaje que lo enuncia: Luzmán es un pícaro ridículo a quien Lope no tendrá problemas en escarnecer y castigar de la manera más ejemplar (vv. 2842-3001), y, por tanto, sus actos y palabras deben ser entendidas bajo ese prisma. El dramaturgo madrileño se regodea en la caracterización del personaje a través de rasgos risibles: por ejemplo, vanidad hiperbólica de Luzmán — «el talle, a cuenta del cielo. / Y el cielo no pudo errar, / que cuando tomo consejo / con el cristal del espejo / el sol no puedo envidiar» (vv. 12-16)—; su extenso conocimiento de afeites femeninos (vv. 53-86), que provoca el rechazo de su criado Tristán — «Deja esas vanas quimeras / que no es tu honor decillo / ni se puede comprender / proceso tan infinito» (vv. 87-90), y después, «Más sabes que una mujer» (v. 92)—; o, incluso, su desmesurado interés, que lo lleva a rechazar la belleza en detrimento del dinero: «lo que Luzmán desea / es mujer mayor y fea, / mas rica y noble mujer, / que mi intención es pelar / mujeres de este jaez» (vv. 478-482). Y, por poner un último ejemplo significativo, Lope se burla de que el personaje, en su afán de fingir un origen noble, no sea capaz de elegir entre los apellidos que le sugieren sus criados, sino que los encadena todos

6. Incluye en la lista, además del citado, los sonetos esdrújulos de Los melindres de Belisa (vv. 423437), La viuda valenciana (vv. 339-352) y Los locos por el cielo (vv. 2253-2266).

7. Vale la pena precisar, sin embargo, que en las fechas que nos conciernen no podríamos hablar de "poetas cultos» en el sentido de «gongoristas», pues la polémica todavía no se había desatado. Por otra parte, Fosalba (2002: 154) apunta que los versos esdrújulos cómicos de Lope «se concentran en sus empeños por lanzar dardos desde sus comedias contra el abuso de cultismos por parte del gongorismo (como en La niña de plata: 'Ya quería / correr la noche su cortina lóbrega, / y aparecer la luz del alba cándida, / como dicen poetas en esdrújulos, / cuando salió de ver la niña el príncipe’)». 
con un resultado absolutamente ridículo: «Ya el nombre me alboroza: / don Luzmán de Toledo y de Mendoza / Girón Enríquez Lara» (vv. 1655-1657). ${ }^{8}$ No necesitamos más ejemplos para ilustrar cómo Lope creó un personaje risible, cómico, que haría sobre los escenarios las delicias de grandes y chicos. Si se me permite una comparación anacrónica, Lope trata a Luzmán de una manera muy cercana a la que utiliza Valle-Inclán para sus fantoches esperpénticos; o, para volver a términos más aceptables cronológicamente, a la imagen que se presenta del capitán Spavento en la commedia dell'arte o, incluso, de los métodos quevedianos para burlarse de sus personajes.

Por otra parte, encontramos en una obra contemporánea de Lope algunas claves para entender el comportamiento de nuestro Luzmán. Me refiero, por supuesto, a El viaje entretenido de Agustín de Rojas Villandrando, autor que, según su propio texto, comparte con nuestro pícaro el apodo que da título a la comedia lopesca: caballero del milagro. ${ }^{9}$ El paralelo entre el personaje que crea Rojas Villandrando y Luzmán no se queda en el mero mote, sino que trasciende a ciertos comportamientos, como queda bien claro en la «Loa XXX», cuando le explica a una vieja su apodo: «son mis milagros, señora, / milagros acá en la tierra, / que aboban a las mujeres / y a los bobos embelecan» (ed. J. Joset 1997, II, p. 102); después, apunta a su carácter camaleónico y avispado, también común: «Soy con damas Alejandro, / con los sabios, trato veras, / con los arrogantes, grave, / con los humildes, oveja; / con los avaros soy Midas, / con los magnánimos, César, / con los galanes, Narciso, / con los soldados, la guerra, / con los oradores, Tulio, I con los poetas, poeta» (ed. J. Joset 1997, II, p. 104). Estas palabras de Rojas Villandrando nos ofrecen - y reconfirman - una lectura general del actuar de Luzmán y de la particular enunciación del soneto. Recordemos una vez más la situación concreta: los dos antagonistas de Luzmán, Leonato y Camilo, saben que han sido engañados previamente por el pícaro y conocen sus dotes de seductora e irresistible floritura verbal y retórica, a la que temen. Sobre aviso, pues, con mal ánimo, malas caras y malos oídos, se enfrentan a él y su soneto. Luzmán quiere regalar los oídos de Leonato. Y a pesar de estar advertidos, y de haberlo reconocido ante el público, vuelven a caer seducidos en las redes de los catorce versos, como muñecos fantoches incapaces de reaccionar de manera distinta ante una misma situación. El mismo Bergson (1991: 68-70), en su clásico estudio Le rire. Essai sur la signification du comique (1900), apuntaba el carácter puramente cómico

8. Inevitable recordar un pasaje famoso del Buscón de Quevedo, donde el protagonista conoce, camino a Madrid, a Toribio: «Preguntele cómo se llamaba y adónde iba y a qué. Dijo que todos los nombres de su padre: don Toribio Rodríguez Vallejo Gómez de Ampuero y Jordán. No se vio jamás nombre tan campanudo, porque acababa en dan y empezaba en don» (ed. F. Cabo Aseguinolaza 2011: 94).

9. Se ha preguntado cierta parte de la crítica si Agustín de Rojas llegó a representar la obra de Lope, véase al respecto Domènech (2007) y, más recientemente, Restrepo y Valdés (2016). Queda todavía por estudiar la relación histórica que pudo haber entre Rojas Villandrando y la comedia de Lope. 
de la repetición de situaciones: ${ }^{10}$ "La répétition. - Il ne s'agit plus, comme tout à l'heure, d'un mot ou d'une phrase qu'un personnage répète, mais d'une situation, c'est-à-dire d'une combinaison de circonstances, qui revient telle quelle à plusieurs reprises, tranchant ainsi sur le cours changeant de la vie». Y el efecto de este recurso es todavía más acusado si es protagonizado por personajes fantoches: «Le pantin à ficelles. -Innombrables sont les scènes de comédie où un personnage croit parler et agir librement, où ce personnage conserve par conséquent l'essentiel de la vie, alors qu'envisagé d'un certain côté il apparaît comme un simple jouet entre les mains d'un autre qui s'en amuse» (Bergson 1991: 59). Así, siguiendo a Bergson, la repetición de una situación, protagonizada por los mismos personajes, remarcaría su carácter de fantoche, de muñeco manejado por hilos y, por ende, provocarían la risa del público. Estos conceptos no han sido ajenos al estudio de nuestro teatro de los Siglos de Oro. Así lo demuestran las palabras de Cabańas (1991: 299) sobre los entremeses quevedianos, quien, siguiendo a Mancini, apunta que «Estos temas [cómicos, como las burlas, los robos ingeniosos] aparecen plasmados a nivel estructural de forma que refuerzan su potencialidad cómica, con la presencia de artificios geométricos útiles para subrayar el carácter jocoso de la trama: escenas duplicadas, triplicadas, etc. [...] la repetición favorece la producción de comicidad» (1955: 91). El soneto esdrújulo pronunciado por Luzmán sobre el escenario como repetición de burlas pasadas demuestra perfectamente el poder adulador del pícaro que "a los bobos embelecan», como decía Agustín de Rojas.

Por otra parte, la declamación del soneto viene introducida por un parlamento del mismo Luzmán que subraya no solo la comicidad del pasaje basada en la repetición de una palabra — rasgo de lo cómico, por otra parte, también subrayado por Bergson (1991: 55) cuando se ocupa del diable à ressort—, sino que también pone de manifiesto la pedantería y el elitismo ridículo e hiperbólico del protagonista. ${ }^{11}$ Veamos la escena:

$\begin{array}{ll}\text { LuZMÁN } & \text { ¡Oh, bravo concepto! } \\ & \text { ¡Oh, musas bien empleadas! } \\ \text { CAMilo } & \text { ¿Qué aguardas, que no le das?) } \\ \text { LuZMÁn } & \text { ¡Oh, santo Apolo que estás } \\ & \text { sobre las nubes doradas!, } \\ & \text { si me ayudas, te prometo } \\ & \text { hacerte un elogio cuando...) } \\ \text { ¿Cómo nos dejó cenando, } & \text { qué digo...? } \quad \text { ¡Oh, bravo conceto! } \\ \text { LEONATO } & \text { ¿Conceto? ¡No dije bien! }\end{array}$

10. Cándano Fierro (2000) utiliza los conceptos de Bergon en el estudio de la comicidad en la Edad Media.

11. Véase Fernández Rodríguez y Valdés (en prensa). 


\begin{tabular}{|c|c|}
\hline CAmilo & $\begin{array}{l}\text { Concepto, con p, es mejor... } \\
\text { ¡Ah, señor conceteador, } \\
\text { escúcheme a mí también! }\end{array}$ \\
\hline LuZMÁN & $\begin{array}{l}\text { Ya me ayudas, en efeto... } \\
\text { (¡Mira, Apolo, que son dos!) }\end{array}$ \\
\hline CAMilo & (¿Sacúdole? \\
\hline LEONATO & ¡No, por Dios! \\
\hline CAMilo & ¿Cómo no?) \\
\hline LuZMÁN & $\begin{array}{l}\text { ¡Oh, bravo conceto! } \\
\text { Ya el soneto es acabado: } \\
\text { oíd, que decirle quiero. (vv. 1329-2347) }\end{array}$ \\
\hline
\end{tabular}

La repetición mecánica del sintagma «iOh, bravo conceto!», con su variante ("concepto»), así como la «interesante observación de Luzmán como testimonio de los hábitos de pronunciación, más pedante y elitista con grupo culto, o más vulgar y extendida con su reducción" (Restrepo y Valdés 2016), ${ }^{12}$ y la consiguiente burla que despierta en Camilo, «señor conceteador», debían ir acompañadas de unos gestos actorales que marcaran de manera física y gráfica para el espectador el carácter cómico del pasaje. A esta sazón, no podemos olvidar las ilustradoras palabras de Cabańas a propósito de la comicidad en los entremeses de Quevedo que se pueden aplicar a nuestro caso:

En cualquier caso, hemos de tener en cuenta que gran parte de la comicidad derivada de las acciones de los personajes se nos escapa inevitablemente: a través de la lectura apenas podemos intuirla. Dada la escasez de acotaciones de estas piezas en general, y de las referidas a gestos, ademanes, entonación, etc., en particular, debemos suponer que los actores añadirían según sus habilidades personales todo este tipo de matices que potenciarían fuertemente la dimensión cómica de la palabra. (1991: 300)

Por otra parte, podemos apoyar nuestra argumentación en la descripción de una situación cómica que hace López Pinciano en la «Epístola nona» de su Philosophia antigua poética. En el marco del género cómico, y después de que Fadrique ofrezca una explicación a lo que produce risa — «esta materia de la risa es fundada en torpeza y fealdad» (ed. Carballo Picazo 1973: 32) y, más adelante, «lo ridículo está en lo feo» (ed. Carballo Picazo 1973: 33)—, Pinciano plantea una situación cómica y pregunta acerca de lo que permite adscribirla a este tipo:

¿Qué obra fea hubo en esto que diré, lo cual causó mucha risa? Estaba un labrador encima de un pollino, comiendo un pastel, y dos estudiantes se pusieron en medio; el uno de los cuales le preguntó cierta cosa, y, en tanto que el labrador respondió al uno, el otro le sacó la carne del pastel sutilmente, y se la metió en una escarcela que

12. Véase Clavería Nadal (1990: 99-142) y Sánchez Lancis (1998). Silvestri (1992) aporta datos interesantes sobre la figura del pedante en el teatro italiano del XVI. 
traía; el labrador pasó adelante dos o tres pasos y, cuando vio la cáscara sin meollo, se quedó mirando al cielo, como que algún pájaro se la hubiera llevado. El robador y encubridor fueron de risa finados. (ed. Carballo Picazo 1973: 36-37)

El argumento cómico descrito por Pinciano recuerda el «Passo quinto» del Deleytoso de Lope de Rueda y, al mismo tiempo, un entremés lopesco inserto en la comedia Arcadia (vv. 1538-1622). Si bien es cierto que nuestra escena no es idéntica a las citadas, la explicación que da Fadrique a la escena cómica planteada por Pinciano sirve perfectamente para explicar nuestro pasaje: «Cuento es ridículo ese, dijo Fadrique, y mucho, porque tiene lo feo doblado: fealdad de parte del labrador, que fue la ignorancia, y fealdad de parte de los estudiantes, que fue la picardía» (ed. Carballo Picazo 1973: 37). Así, encontramos las mismas fealdades cómicas en el episodio de nuestra comedia: Camilo y Leonato son ignorantes como el labrador de López Pinciano, mientras que Luzmán tiene la picardía de los estudiantes del ejemplo citado. Así, no parece caber duda acerca del sentido y de la función cómica, o incluso farsesca, de la escena previa ("conceto» / "concepto»).

Todos estos recursos cómicos —desde las escenas duplicadas o triplicadas de burlas ingeniosas, pasando por las fealdades cómicas, hasta la evidente pedantería de Luzmán que prefiere la pronunciación culta «concepto» en detrimento del popular "conceto»- van creando una estructura escénica de jocosidad in crescendo en la que el soneto esdrújulo funciona como coronación cómica, el summum del ridículo. Los versos de Luzmán son evidentemente exagerados, desmesurados, pedantes. Anota Rico (2004: 1027 n.), a propósito de los esdrújulos cómicos y encadenados que pronuncia la Dolorida y Sancho en la corte de los duques (Don Quijote, ed. Rico 2004, II, xxxviII: 1027) que «el superlativo en -ísimo, que se prodiga en el parlamento, era considerado pedante y cursi». ${ }^{13}$ Pero el sentido cómico, o por lo menos negativo, venía de muy atrás. Cabe recordar que desde 1580, en opinión de Sánchez de Lima (1944: 77) en su El arte poética en romance castellano, "todos los más de esta manera, que son aborrecibles a todos generalmente». Lope pone en boca de Luzmán dos: «invictísimo» y "riquísimo». Y es que la pedantería resalta en la hinchazón de los términos que utiliza el improvisado poeta: "armífero»; "fiero cismático y herético»; «falso alárabe profético»; "belífero», "cristífero», "mahomético», "salutífero», por utilizar solo los casos más flagrantes de los cuartetos. Navarro Tomás (1974: 262) supuso «que el efecto cómico que hoy produce en español la insistencia en la rima esdrújula no había desarrollado aún este sentido». Nuestro caso demuestra lo

13. Alatorre (2007: 223 n.), haciéndose eco de este pasaje y del poeta del Coloquio de los perros, dice que a "Cervantes le hacían cosquillas los esdrújulos». Tampoco tiene desperdicio la descripción del libro inédito que el poeta de marras describe: «todo en verso heroico, parte en octavas y parte en verso suelto; pero todo esdrújulamente, digo, en esdrújulos de nombres sustantivos, sin admitir verbo alguno» (ed. J. García López 2001, p. 618). 
contrario: la exageración del soneto, su pompa y su ampulosidad, hacen evidente que Lope en 1593 ya vislumbraba con claridad ese efecto cómico. Un efecto que, a buen seguro, podía ser llevado al límite a través de una puesta en escena tanto por Luzmán, con una declamación hiperbólica del soneto, como por los otros dos personajes en su redacción. Quizás no sobre recordar que Reid observó bien que «There is some evidence to indicate that Lope, at least in his later years, associated the use of the esdrujulos with the extravagant vocabulary of cultismo» (1939: 284, cursiva del original). ¿Es este un caso tempranísimo? Por otra parte, no es difícil imaginar esta farsa representada por unos payasos.

Ahora bien, ¿estamos ante una rara avis? Sabemos de sobra que Lope escribió abundantes versos esdrújulos, como bien apunta Reid: «In a very summary survey of his published works I have come upon nearly eight hundred lines in which proparoxytones were used intentionally in long series» (1939: 280). Aporta, además, una extensa lista de comedias: La pobreza estimada (15971603), ${ }^{14}$ La amistad pagada («anterior a 1604, probablemente 1599?-1603?»), El sol parado (1596-1603), El remedio en la desdicha (1596-1602), ${ }^{15}$ Angélica en el Catay (1599-1603, probablemente 1599), Palacios de Galiana (1597-1602), Los locos por el cielo (1598-1603), Los comendadores de Córdoba (anterior a 1598, probablemente 1596-1598), El Perseo (1611-1615), Los amores de Albanio y Ismenia (1590-1595) —llamada por otro nombre La pastoral de Albania_, La francesilla (1596), El genovés liberal (1599-1608, probablemente 1599?-1603), El caballero del milagro (1593), Baarlán y Josefat (1611), ${ }^{16}$ La viuda valenciana (1595-1599), ${ }^{17}$ Adonis y Venus (1597-1603) y Los melindres de Belisa (16061608). Una búsqueda en ARTELOPE nos arroja una comedia más, La fe rompida (1599). Lope, pues, durante la última década del xvi y los primeros ańos del XVII utilizó, solo en sus comedias, con cierta frecuencia los versos esdrújulos. ${ }^{18}$

Más allá de las fechas - y nótese que la gran mayoría se compusieron en la bisagra, difícil de precisar los años exactos, entre el siglo XVI y el XVII-, de los textos citados encontramos, por lo menos, tres usos del esdrújulo en un sentido claramente cómico, sin tener en cuenta, por supuesto, el de Luzmán. El primero de ellos aparece en La francesilla, comedia de la que tenemos certeza de su fecha de composición pues el manuscrito Gálvez que se conserva contiene dicha información, cuando un hospedero, en el segundo acto, alaba las cualidades de su po-

14. Sigo, para todas las fechas, el clásico trabajo de Morley y Bruerton (1968) y que recoge ARTELOPE en la entrada dedicada a cada una de las comedias, pero no la fecha de La francesilla, que tomo del mss. Gálvez (Iriso Ariz 1998: 107).

15. La fecha de la comedia parece ser, en realidad, 16 de octubre de 1596, fecha que anota Gálvez para Abindarráez y Narváez, considera hoy en día como la misma comedia que El remedio en la desdicha, para esto véase Fernández Rodríguez (2014: 290).

16. Crivellari (2015: 79).

17. Teresa Ferrer (1990: 9) propone 1599-1600.

18. Véase también Serralta (2008). 
sada - «iMil veces vengan norabuena príncipes, / que esta es posada de famosos césares!» (vv. 1130-1131) — en cómicos versos. Para muestra un botón: «iDareos el mismo fénix, el perícano! / Hay ginebradas, salchichón de búfalo, / tortadas, manjar blanco y almojábanas, / truchas, barbo, salmón, róbalo y sábalo, / aunque pescado y carne niega el médico» (vv. 1158-1162). Feliciano, contagiado, pero irritado ante la cadena de esdrújulos, le espeta: «Paso, tanto estrépito!» (v. 1140). McGrady anota que estos «versos sueltos esdrújulos constituye un alarde de destreza técnica, a la vez que produce un efecto de gran comicidad» (1981: 121 n.). Por su parte, Reid apunta una particularidad de este fragmento: "This passage offers a feature which is rare among the esdrújulos: the majority of the proparoxytones are popular words which refer to commonplace matters: sábanas, tréboles, azúcares, tórtolas, ánades, almojábanas, sábalo» (1939: 284).

Por los mismos años, antes de que se decretara el cierre de los teatros, Lope compone otra comedia, Los comendadores de Córdoba, donde hay, repitiendo lo hecho en El caballero del milagro, un soneto esdrújulo que cierra el primer acto pronunciado por un cómico criado:

\section{Sale Galindo a lo gracioso de noche, con casco y rodela.}

GALINDo Si en el poyo más limpio o más pestífero de tu cocina fresca y aromática duermes por no escuchar la dulce plática deste cautivo pobre lacaífero, despierta de mi pena el son mortífero, Medea pucheril, Circe fregática, pues eres la picina y la probática que me ha de dar remedio salutífero.

Vuélvelos pernizarcos ojos rígidos a este oxizambo amante en mil recámaras, el alma lleno de éticas y tísicas.

Mira que de tener los pies tan frígidos podrá señora que me den cámaras, que para ti serán crueldades físicas. (vv. 932-945) ${ }^{19}$

Rafael Ramos (2004: 254) incluye este soneto dentro de aquel ciclo de poemas dedicados a las fregonas, una moda durante los últimos ańos del siglo xvı, de la que da abundantes muestras para concluir: «Es evidente, pues, que en la época se multiplicaron los poemas sobre fregonas, y no solo para criticarlas sino también, irónicamente, para mostrarlas como modelo de enamoradas" (Ramos 2004: 257). En la comedia, Galindo pronuncia los versos en honor a Esperanza, una esclava.

19. Véase Laplana (1998) y (1999) y Ramos (2004), quien da noticia de la aparición de este soneto en un cancionero manuscrito de finales del siglo xvI, lo que demuestra la difusión que tuvo el soneto antes de la aparición de la comedia en la Parte II. 
Por otra parte, frente a los esdrújulos cotidianos que utiliza Lope en La francesilla, resaltan aquí algunos cultismos: pestífero, lacaífero, fregática, probática, salutífero. Voces muy cercanas a las utilizadas por Luzmán en la comedia de $1593 .{ }^{20}$

Un poco posterior, aunque imposible determinar qué tanto, ${ }^{21}$ encontramos en El genovés liberal, un soneto esdrújulo en italiano macarrónico, que Reid calificó de «a bit of playful nonsense» (1939: 283): ${ }^{22}$

El mio desire.
Drusila, in questo nostro vivir picolo
fede in amor fu sempre reguardebole;
ancor que parto, espetami amorebole,
que ir anima te reste por testicolo.
Ya temo in questo mar solo un pericolo:
Marceloes bel putin e tu sey debole;
se tu la fay del tuo meretebole,
yo pillo el core e de un forca empicolo.
Quando senza di me vendray lo estabolo,
non te adornare el biso, non te specula
guarda, que si per te me porta el diabolo
il tuo amante perderás in secula. (vv. 1290-1302)

Ante la dificultad de entenderlo, Drusila nos resume lo imprescindible: «Digo, Bruneto, que estaré en tu ausencia / más firme que una roca» (vv. 1303-1304). Canonica-de Rochemonteix se ocupa de todo el pasaje y señala certeramente su sentido: "La despedida de los amantes es un tópico de la literatura de tono alto (lírica, épica) y el solo hecho de transponerlo al plan de la intriga secundaria representa una mezcla estilística densa en comicidad» (1991: 174). Es precisamente

20. Por los mismos años en que Lope redacta esta comedia, tenemos otro ejemplo de esdrújulos en Viuda, casada y doncella (22 de octubre de 1597, según atestigua el apógrafo de Gálvez) que Feliciano, uno de los personajes, resalta como cómicos: «iPor Dios, que estáis de fiesta echando esdrújulos!» (v. 2645). Véase la nota de McGrady (2006: 187) en su edición y el excelente artículo de Fernández Rodríguez (2016) sobre la comedia y los guiones métricos. Debo esta referencia a este último, por tanto, y de nuevo, le agradezco sus valiosísimos aportes.

21. Morley y Bruerton (1968: 332), como ya he dicho, proponen como fecha de redacción «1599-1608, probablemente 1599?-1603». No aparece, sin embargo, en la primera lista del Peregrino (1604), pero sí en la segunda (1618). Las listas se pueden consultar en Tubau (2004: V-XIx). 22. Levi (1935: 66) apunta que no se trata de un soneto, sino de «quartine di sdruccioli»; Canonicade Rochemonteix, por su parte, se inclina, con Otto Jörder (1936) y Reid (1939), por la identificación del pasaje como un soneto, teniendo en cuenta la rima y la estructura: «Desde el punto de vista estrictamente métrico pues, todo nos induce a pensar que la intención del poeta era la de componer un soneto, que por algún motivo no ha logrado su forma poética completa quedándose en el estado de embrión» (1991: 179). Más adelante aventura una explicación: «es a nivel estilístico que se pueden aprehender las razones de este aborto. Lope ha elegido una de las formas más difíciles [...]. Es evidente la extraordinaria dificultad de encontrar rimas en una composición de este tipo, incluso para autores de lengua materna italiana» (Canonica-de Rochemonteix 1991: 180). 
en este contexto donde el difícil soneto debe inscribirse. Así pues, Lope escribió a finales del xvi y comienzos del xVII, al menos, cuatro textos cómicos en esdrújulos, por lo que podemos afirmar con certeza que nuestro soneto de El caballero del milagro no es, ni mucho menos, una rara avis. Con esto no quiero decir que Lope fuera ajeno al uso de los esdrújulos en tono serio, más bien que utilizaba el verso como mejor le convenía, aprovechando también su filón cómico.

Ahora bien, habiendo determinado el carácter puramente cómico de nuestro soneto esdrújulo y de haberlo ubicado en un contexto en el cual Lope hizo un uso moderado del recurso - con otros tres textos documentados a los que cabría sumar «Baja del monte el agua despeńándose» de La viuda valenciana (vv. 339352), según Ramos (2004: 261)—, ¿cabría pensar, además, que tenga un sentido paródico? La pregunta es posible plantearla a la luz de las reminiscencias que suscita el soneto de Luzmán de una canción esdrújula gongorina —especialmente de la tercera estrofa - y que, extrańamente, la crítica, que yo sepa, nunca ha siquiera insinuado. Me refiero a "Suene la trompa bélica», publicada en 1580 en la traducción de Os Lusiadas de Luis Gómez de Tapia auspiciada por la Universidad de Salamanca. Micó (1990) publicó unas espléndidas páginas sobre la canción y sus circunstancias. Recordemos el tempranísimo texto de Góngora:

Suene la trompa bélica

del castellano cálamo,

dándoles lustre y ser a Las Lusiadas,

y con su rima angélica

en el celeste tálamo,

encumbre su valor sobre las Híadas,

Napeas y Hamadríadas:

con amoroso cántico

y espíritu poético

celebren nuestro bético

del Mauritano mar al mar Atlántico,

pues vuela su Calíope

desde el blanco francés al negro etíope.

Aquí la fuerza indómita

del Pacheco diestrísimo

descubre de su Rey el pecho y ánimo,

la India deja atónita

con su valor rarísimo,

y al Samorín soberbio, pusilánimo;

muéstrase aquí magnánimo

Alburquerque y solícito,

capitán integérrimo

que al amador misérrimo

crudamente castiga el hecho ilícito,

y a Goa y supoténcïa

dos veces la sujeta a su obediencïa.

Almeida, que a los árabes 
con la venganza hórrida

sus muros y edificios va talándoles,

y a los rumes y alárabes,

debajo de la Tórrida,

con valerosa espada domeñándoles,

y mayor pena dándoles

con el hijo belígero

que en el seno cambáico

contra el moro y hebráïco

muere mostrando su furor armígero,

sirviéndole de túmulo

de Mamelucos el sangriento cúmulo.

Cuanta pechos heróïcos

te dan fama clarífica,

oh Lusitania, por la tierra cálida,

tanta versos históricos

te dan gloria mirífica

celebrando tu nombre y fuerza válida:

dígalo la Castálida,

que al soberano Tápïa

hizo que (más que en árboles,

en bronces, piedras, mármoles)

en su verso eternice tu prosápïa,

dándole el odorífero

lauro por premio del gran dios lucífero. (ed. Micó et al., vv. 1-52)

Explica Micó, con solvencia, los principales pormenores del poema: «En su elogio del traductor de Camóes, Góngora recrea sumariamente, desdeñando pasajes más famosos o de carácter menos heroico, unos pocos pasajes de Os Lusíadas» (Micó 1990: 27); «Góngora quiso dar la talla de poeta épico arrimándose a las musas de Cairasco» (Micó 1990: 26). Y años después: «En los casos anteriores a 1580 (quizá con la única excepción, decisiva, de Cairasco) se usó siempre [el verso esdrújulo] en poemas amorosos y de ambiente pastoril; Góngora, en cambio, le da altura épica» (Micó 2010). Además, propone Micó los modelos que sirvieron a Góngora y que ya he adelantado: la canción que comienza «En tanto que los árabes» y a su respuesta «Ha sido vuestra física» (1990: 26), atribuidas a Cairasco y al licenciado Dueñas, aunque la crítica ha supuesto que ambos poemas podrían ser del poeta canario. ${ }^{23} \mathrm{Las}$ tres canciones tienen coincidencias estupendas: el mismo tipo de estrofa:

la estancia de trece versos $a b C, a b C$ : $c$ dee $D f F$, uno de los esquemas más ilustres de la canción petrarquista [...] el uso de bastantes consonancias proparoxítonas iguales [...] que no puede explicarse por el aire de familia [...]. Veámoslas: árabes; alárabes, Castáli-

23. Véase Zerolo (1897), Navarro Durán (1982), Brito Díaz (2001: 50) que resume la cuestión y aporta pertinente bibliografía, finalmente Alatorre (2007: 198-200). 
da; inválida, etíope; Caliope, árboles; mármoles (esto es, una rima distendida o imperfecta), Atlántico: cántico, ánimo, pusilánimo, lícito, solícito, cálamo, tálamo. Claro que esas rimas son como cerezas, que unas a otras se enredan; pero eso no es todo, porque las «canciones esdrújulas» de Dueñas y Cairasco también comparten con la de Góngora sintagmas reveladores, ideas afines y hasta los cultismos que asombraban con razón al maestro Dámaso Alonso: furor armígero : beligero (34 y 37); del árbol odorifero : os coronó en planeta más lucifero (51-52); hórrida: debajo del norte y de la tórrida (28 y 31); amador misérrimo (23); Y al que en dorado tálamo / iba por el Zodíaco (5). (Micó 1990: 26)

Un paréntesis: recordemos que Lope muchos años después, en 1630 en su Laurel de Apolo (II, vv. 59-61), decía que «alborotó las Musas de Cairasco, / que esdrujular el mundo / amenazaron con rigor profundo». ${ }^{24}$ Aparte de la memoria de Lope, conviene apuntar que el soneto de Luzmán converge con los anteriores en «sintagmas reveladores», aunque pocos, por usar palabras de Micó: armífero (por armígero) : belifero (por belígero), alárabe; y, con la canción gongorina: valerosa espada : valeroso armifero, además de los versos finales donde riman, en los dos textos, túmulo : cúmulo. No cabe suponer, a la luz de los textos y de las circunstancias históricas - y que yo sepa nadie lo ha sugerido siquiera-, que el soneto de Luzmán esté emparentado directamente con los de Cairasco, si acaso indirectamente pasando por el filtro gongorino.

Si bien la cantidad de sintagmas concordantes no es abrumadora, una comparación del soneto esdrújulo de Lope y la tercera estrofa de la canción del joven Góngora — dedicada a las hazańas de Almeida — es reveladora: para empezar, domina en ambas lo que Micó llama «altura épica»; ambos textos están protagonizados por un héroe cristiano que lucha contra los infieles - moros y judíos - en feudo enemigo — «sus muros y edificios va talándoles»; «el pendón católico y cristífero / has puesto sobre el muro mahomético»—. Aunque el destino de ambos héroes es distinto - Almeida muere en la batalla, mientras que el «Leonato ilustre» campa a sus anchas por las calles romanas-, ambos gozan, en estos versos, de admirables honras fúnebres: «y en muerte como a mílite evangélico / dos mil banderas honrarán el túmulo»; «sirviéndole de túmulo / de Mamelucos el sangriento cúmulo». Sus estructuras, además, son similares: las hazañas épicas que protagonizan como defensores de la cristiandad contra los infieles los llevan a merecer fama y honras militares simbolizadas en sus tumbas. Pero, recordemos, los destinatarios de semejantes alabanzas son opuestos: el primero heroico, mientras que el segundo, según se representa en la comedia, es un ingenuo, incluso tonto, que cae una y otra vez en la misma treta. Así, la estrofa gongorina y el soneto de Luzmán se acercan, pero, al

24. Palabras de Lope que recuerda, oportunamente, Micó (1990: 26). Por otra parte, Lope menciona de nuevo a Cairasco en la Dorotea (ed. McGrady, IV, III, p. 301); y, en la misma obra, aunque muy tardía, sus personajes condenan los versos esdrújulos sin ambages: «LUDovico. Eso no, porque las voces esdrújulas son hinchazón del verso. / Julio. No, sino lobanillo [un tumor en la cabeza, según Covarrubias]» (Dorotea, IV, III, p. 300). 
mismo tiempo, se distancian notablemente en su sentido: el del primero, serio y el del segundo burlesco, como ya hemos tenido oportunidad de demostrar.

Contamos, además de los argumentos literarios que hemos esbozado, con otros de carácter más bien histórico que apuntan en la misma dirección. Como ya he expuesto, el Caballero del milagro fue redactada en los últimos meses de 1593. Si bien es bastante conocida la conflictiva relación entre los dos poetas en el siglo XVII, ${ }^{25}$ las hostilidades entre ambos pueden remontarse, como señala Pedraza, a «los ańos del romancero juvenil» (2009: 50). Y, precisamente, en este ámbito poético y literario - el del nuevo romancero donde dos de las figuras más deslumbrantes son Lope y Góngora - nos quedan, por lo menos, dos claros enfrentamientos: el primer caso documentado podríamos denominarlo, a la luz de los primeros versos, como la polémica equina; el segundo sería la polémica fluvial entre el Tajo y el Guadalquivir. ${ }^{26}$

Lo que aquí he llamado polémica equina se compone de la parodia gongorina al romance morisco atribuido a Lope "Ensílleme el potro rucio» y que el poeta cordobés titula «Ensílleme el asno rucio». El texto del poeta madrileño ha sido datado alrededor de 1583, sin embargo, no se publica por primera vez hasta 1589 en la Flor de varios y nuevos romances (Barcelona) de Moncayo; pero es en la siguiente edición de 1591 - y fíjense en la cercanía con la redacción de $E l$ caballero del milagro - donde se incluye, a continuación de este, el de Góngora con un significativo epígrafe: «romance contrahecho» (Fuentes II, fol. 7), ambos sin firma. ${ }^{27}$ Lo explica así Carreño (2013: 50): «La alteración de 'potro' (Lope) en 'asno' (Góngora), del 'Alcaide de los Vélez' por 'Antón Llorente' [...] evidencia de la idealización del romance de Lope a la descripción de una realidad rústica, y hasta grotesca, que socaba radicalmente el tópico del amor leal y el de la fidelidad en la ausencia». ${ }^{28}$ Por otra parte, este ataque del cordobés ha sido enmarcado en «las sátiras y parodias contra el romancero morisco» (Sánchez Jiménez 2014: 160). ${ }^{29}$ Orozco apunta que estos romances «se pueden considerar arranque de la actitud de rivalidad» (1973: 28) entre Lope y Góngora. Si bien la autoría

25. Véanse Orozco (1973), Quintero (1991: 47-67), López Viñuela (1993), Sánchez Jiménez (2006: 27 y ss.) y (2014), entre otros.

26. Cito los romances de Lope de la edición de Sánchez Jiménez (2015); los de Góngora a partir de la edición de Carreño (2013).

27. Carreño (2013: 229), siguiendo al ms. Chacón, data el romance gongorino en 1585. Es decir que tardaría más o menos seis años en aparecer en letra de molde, significativamente, como he apuntado, acompañando a su modelo.

28. Orozco, que reproduce los dos textos, concluye que «Frente al entusiasta y brillante romance de Lope surge la parodia de Góngora, que, como hemos visto, va rehaciendo la creación del madrileño con una intención paródica, haciendo a la vez ironía del género y de la concreta versión de aquél; va, diríamos, dando un tirón hacia abajo, hasta el plano de lo burlesco de cada rasgo exaltado del romance morisco» (1973: 36).

29. El mismo Sánchez Jiménez (2014) analiza muy bien la polémica y sus connotaciones. Véase, además, Carrasco Urgoiti (1986). 
de Lope ha sido fuertemente cuestionada desde Fernández Montesinos (1969: 281) hasta, más recientemente, Pérez López (2012: 109-110), quien atribuye el romance, a partir de un testimonio antiguo, a Pedro Liñán de Riaza, amigo del Fénix, no es este motivo para desechar el posible rifirrafe. El mismo Pérez López señala que «no habría que descartar que todo el ciclo de Azarque [protagonista del romance citado] fuera el producto de la colaboración de los dos amigos» (2012: 110), quienes seguro lo hicieron en el ciclo del pastor Simocho. Y sigue: «Los dos amigos trabajan juntos: fundaron una academia en Toledo en la que ambos, Riselo y Belardo, reinaban como poetas máximos, se intercambiaron sonetos, larguísimos poemas en tercetos, se elogian y se defienden el uno al otro en multitud de ocasiones» (Pérez López 2012: 110). Por tanto, la parodia de Góngora - fuera contra uno o contra otro- con seguridad habría despertado la todavía insipiente rivalidad entre ambos escritores.

El mismo año en que se publican juntos los romances citados, es decir 1591, como se desprende del mss. Chacón, el poeta cordobés redacta «en caliente», según palabras de Orozco Díaz (1973: 61), «A vos digo, señor Tajo».30 Los versos del cordobés no tienen ninguna referencia al poeta madrileño, pero la imagen que da del famoso río - y por tanto de la ciudad de Toledo, de la que se sentía tan cercano- ${ }^{31}$ quizá le molestó: «Vos, que en las sierras de Cuenca / (mirad que humildes principios) / nacéis de una fuentecilla / adonde se orina un risco» (vv. 21-24). ${ }^{32}$ No tardaría Lope en responder a Góngora con su «Bien parece, padre Tajo»: lo demuestra que ambos textos se publicaran seguidos en el Ramillete de flores. Quarta, Quinta y Sexta parte de Flor de Romances nuevos, impreso en Lisboa en 1593 por Pedro de Flores (apud. Orozco Díaz 1973: 63). Y lo que es una rareza: ambos con firma. Vale la pena recordar algunos de los versos contrahechos del romance lopesco:

\footnotetext{
Gran locura fue querer saber si sois bien nacido, y de las sierras de Cuenca daros por asiento el sitio. Y por ser de esto fiscal Guadalquivir, el morisco, que a lo menos, si es hidalgo, no lo dice el sobreescrito,
}

30. Véanse para esta polémica Cossío (1960: 413 y ss.), Orozco Díaz (1973: 60-78) y, más recientemente, Sánchez Jiménez (2014).

31. Véase Orozco Díaz (1973: 62) y Madroñal (2012).

32. La escatológica figura de los ríos castellanos meados es motivo feliz para Góngora y Lope, muchísimos años después, lo recordaba. Eso se desprende de unas palabras de Celia en la Dorotea: «No juzgues a malicia esta pintura breve del lienzo de Sevilla puesto en práctica. ¿¿Pensabas que era el Betis como nuestro Manzanares, río con mal de piedra, todo arenas, por quien dijo don Luis de Góngora, aquel famoso cordobés, que un jumento le orinó el invierno, y otro se le bebió el verano?» (ed. McGrady, II, II, 94-95). Como comenta McGrady (2011: 95 n.), Lope recuerda imprecisamente el famoso verso gongorino que dice «bebióme un asno ayer, y hoy me ha meado». 
con vos se quiere igualar, y con su árabe apellido, que a pesar de tantos tiempos, guardáis el nombre latino (ed. Sánchez Jiménez, vv. 21-32)

Orozco Díaz vio en estos versos un «oportunista ataque personal del madrileño, que se lo lanzó, sin motivo, cuando él [Góngora] sólo le había dirigido hasta entonces burlas e ingeniosidades literarias» (1973: 68). Esta lectura la ha rebatido Sánchez Jiménez, quien pone el énfasis del enfrentamiento en otro punto: «sí [hay] un enfrentamiento de regiones - y sobre todo, de grupos de poetas - asociados a los respectivos ríos, Guadalquivir y Tajo» (2014: 169). Coinciden ambos críticos, sin embargo, en la tesis central de que «El romancero fue uno de los campos de enfrentamiento entre Lope y Góngora, y uno en el que ambos usaron como égida, en serio o en broma, el honor de sus respectivas regiones de origen, lanzando diversas pullas a la contraria» (Sánchez Jiménez 2014: 170).

Tuvieran o no los versos de Lope un carácter de ataque personal, o que sencillamente pusieran en evidencia un enfrentamiento entre grupos de poetas, lo que sí queda del todo claro es que entre los últimos años de la década de los ochentas y comienzos de los noventa Lope y Góngora escenificaron su rivalidad en una serie de combates en el romancero nuevo. El primero de ellos - llamada aquí batalla equina - iniciada por Góngora; mientras que el segundo sería responsabilidad del madrileño. Además, las fechas del último caso citado nos acercan mucho a aquellos meses de noviembre y diciembre de 1593 en que Lope redacta El caballero del milagro y, por tanto, del soneto esdrújulo de Luzmán. Por otra parte, no sobra recordar aquí la definición de parodia que nos ofrece Fadrique - y que explica en buena medida tanto los enfrentamientos en el romancero como el soneto de Luzmán— en la «Epístola cuarta» de la Philosophia antigua poética, de López Pinciano: «La Parodia no es otra cosa que un poema que a otro contrahace, especialmente aplicando las cosas de veras y las graves a las de burlas» (ed. Carballo Picazo, 1973, I, p. 289). Por tanto, es preciso concluir que el soneto lopesco es, aunque encubierto - y así, inexplicablemente, ha pasado siglos desapercibido-, una pulla y una burla a la canción esdrújula que publicara el jovencísimo Góngora en la traducción salmantina de Os Lusíadas. Estamos, pues, frente a un soneto paródico del texto gongorino. Lope, con el soneto de Luzmán, lleva el enfrentamiento a otro ámbito literario donde ya por esos años ejercía, en palabras de Cervantes, la «monarquía cómica»: el teatro. Lo recuerdan oportunamente Fernández Rodríguez y Valdés (en prensa): «En relación al gongorismo, claro, también la comedia se considera palestra, lugar adecuado para el combate». Así pues, nuestro soneto esdrújulo no solo es otro claro ejemplo de la temprana antipatía entre ambos poetas - que no es poca cosa-, sino que, además y sobre todo, es un ejemplo tempranísimo de cómo Lope lleva el enfrentamiento al campo literario donde más destacaría. En todo caso, una rara avis, míresele por donde se le mire. 


\section{Bibliografía}

Alatorre, Antonio, "Versos esdrújulos», Cuatro ensayos sobre arte poética, México, El colegio de México, 2007, 193-306.

Bergson, Henri, Le rire. Essai sur la signification du comique, Paris, Quadrige/ Presses Universitaires de Frances, 1991.

BRITo Díaz, Carlos, «Luz meridional’: Cairasco de Figueroa y la escuela andaluza», en Dicenda. Cuadernos de filología hispánica, 19 (2001), 47-63.

Cabañas, Pilar, «El espectáculo verbal. Comicidad y sátira en los entremeses de Francisco de Quevedo", en Comedias y comediantes. Estudios sobre el teatro clásico español, eds. T. Ferrer Valls y M. V. Diago, Valencia, Universidad de Valencia, 1991, 291-303.

Cairasco de Figueroa, Bartolomé, "Canción de esdrújulos» y «Canción», en $B A E$, XLII, Madrid, Rivadeneyra, 1857, 498-499.

Campo Tejedor, Alberto del, «Trovadores de repente. La improvisación poética en el Siglo de Oro", en eHumanista, 4 (2004), 119-157.

Cándano Fierro, Graciela, La seriedad y la risa. La comicidad en la literatura ejemplar de la Baja Edad Media, México, Universidad Autónoma de México, 2000.

Canonica-de Rochemonteix, Elvezio, El poliglotismo en el teatro de Lope de Vega, Kassel, Edition Reichenberger, 1991.

Carrasco Urgoiti, María Soledad, «Vituperio y parodia del romance morisco en el romancero nuevo", en Culturas populares: diferencias, divergencias, confictos: actas del Coloquio celebrado en la Casa de Velázquez, los días 30 y 1-2 de diciembre de 1983, Madrid, Universidad Complutense, 1986, 115-138.

Carreño, Antonio (ed.), Luis de Góngora, Romances, Madrid, Cátedra, 2013, edición revisada, 2013.

Cervantes, Miguel de, Don Quijote de la Mancha, ed. Francisco Rico et al., Barcelona, Galaxia Gutenberg, 2004, 2 vols.

Clavería Nadal, Gloria, El latinismo en español, Universitat Autònoma de Barcelona, Barcelona, 1990.

Crivellari, Daniele, «Sobre un manuscrito autógrafo de Lope: Barlaán y Josafat», en Revista de Literatura, vol. LXXVII, no 153 (2015), 75-91.

Cossío, José María de, «Notas a romances», en Studia Philologica. Homenaje ofrecido a Dámaso Alonso por sus amigos y discípulos con ocasión de su 60 aniversario, ed. D. Alonso, Madrid, Gredos, 1960, vol. 1, 413-429.

Doménech, Fernando (ed.), Félix Lope de Vega Carpio, El arrogante español o Caballero de milagro, versión de Fernando Doménech y Guillermo Heras, Madrid, RESAD-Editorial Fundamentos, 2007.

Fernández Montesinos, José, Estudios sobre Lope de Vega, Salamanca, Anaya, 1969.

Fernández Rodríguez, Daniel, «Nuevos datos acerca de los repertorios teatrales en el primer catálogo de El peregrino en su patria», en Studia Aurea, 8 (2014), 177-314. 
—, «Escribió Lope guiones métricos? Métrica y segmentación dramática en Viuda, casada y doncella», en Castilla. Estudios de literatura, 7 (2016), 38-68.

Fernández Rodríguez, Daniel y Ramón Valdés, «Esencia y tradición poética en el teatro de Lope» (en prensa).

Ferrer Valls, Teresa (ed.), Lope de Vega, Peribáñez. El mejor alcalde, el rey, Barcelona, Planeta, 1990.

Fosalba, Eugenia, «Égloga mixta y égloga dramática en la creación de la novela pastoril», en La égloga. Encuentros internacionales sobre poesía del Siglo de Oro, ed. Begońa López Bueno, Sevilla, Secretariado de publicaciones Universidad de Sevilla, 2002, 121-182.

Góngora, Luis de, «Suene la trompa bélica», en Todo Góngora, ed. José María Micó et al., 2013. 25-05-2017, <https://www.upf.edu/todogongora/poesia/ canciones $/ 001 />$.

—, Romances, ed. Antonio Carreño, Madrid, Cátedra, 2013, edición revisada.

Iriso Ariz, Silvia, "Estudio de la colección Gálvez: fiabilidad y sentido de los apógrafos de Lope de Vega», en Anuario Lope de Vega, III (1998), 99-144.

Jörder, Otto, "Die Formen des Sonnets bei Lope de Vega", en Beihefte zur Zeitschrift für Romanische Philologie, 86 (1936), 83-97.

Laplana, José Enrique (ed.), Lope de Vega, Los comendadores de Córdoba, en Comedias de Lope de Vega. Parte II, coord. Silvia Iriso Ariz, Lérida, MilenioUniversitat Autònoma de Barcelona, 1998, 3 vols., II, 1023-1174.

—, "Dos notas a Los comendadores de Córdoba de Lope de Vega», en Anuario de Lope de Vega, V (1999), 197-198.

Levi, Ezio, Lope de Vega e l'Italia, prólogo de Luigi Pirandello, Firenze, G.C. Sansoni, 1935.

López Pinciano, Alonso, Philosophia antigua poética, ed. de Alfredo Carballo Picazo, Madrid, Consejo Superior de Investigaciones Científicas, 1973, 3 vols., III.

López Viñuela, Ana Cristina, "Quevedo y 'el pobre Lope de Vega’ en un soneto gongorino", en AISO. Actas III, 1993, 377-385.

Mancini, Guido, Gli entremeses nell'arte di Quevedo, Pisa, Goliardica, 1995.

McGrady, Donald, (ed.), Lope de Vega, La francesilla, Charlottesville, Biblioteca Siglo de Oro, 1981.

- (ed.), Lope de Vega, Viuda, casada y doncella, Delaware, Juan de la Cuesta, 2006.

Micó, José María, «Góngora a los diecinueve años: modelo y significación de la Canción esdrújula», en Criticón, 48 (1990), 21-30.

—, "Comentario a 'Suene la trompa bélica'», en Todo Góngora, ed. José María Micó 2010. 25-05-2017, <https://www.upf.edu/todogongora/poesia/ canciones/1/comentario.html>.

Madroñal, Abraham, «Entre Cervantes y Lope: Toledo, hacia 1604», en $e H u$ manista/Cervantes, 1 (2012), 300-332.

Morley, S. Griswold y Courtney Bruerton, Cronología de las comedias de Lope de Vega. Con un examen de las atribuciones dudosas, basado todo ello en un 
estudio de su versificación estrófica, versión española de María Rosa Cartes, Madrid, Editorial Gredos, 1968.

Navarro Durán, Rosa, «Esdrújulos inéditos de Bartolome Caraisco de Figueroa», en Revista de Filología, Universidad de La Laguna, 1 (1982), 13-34.

Navarro Tomás, Tomás, Métrica española: reseña histórica y descriptiva, Madrid, Ediciones Guadarrama-Labor, 1974.

Oleza, Joan, et al., Base de Datos y Argumentos del teatro de Lope de Vega. ARTELOPE. <http://artelope.uv.es/>.

Orozco Díaz, Emilio, Lope y Góngora frente a frente, Madrid, Gredos, 1973.

Pedraza Jiménez, Felipe B., Lope de Vega. Pasiones, obra y fortuna del "monstruo de naturalezd», Madrid, Edaf, 2009.

PÉREZ López, José Luis, «El romance morisco Ensilleme el potro rucio, atribuido a Liñan, y su parodia», en Revista de Filología Española, XCII (2012), 101-116.

Quevedo, Francisco de, La vida del Buscón, edición, estudio y notas de Fernando Cabo Aseguinolaza, Madrid, Real Academia Española, 2011.

Quintero, María Cristina, Poetry as Play: Gongorismo and the Comedia, Ámsterdam-Filadelfia, John Benjamins Publishing Company, 1991.

Ramos, Rafael, «El cancionero castellano de Ripoll: una rara colección poética de finales del siglo XVI», en Butlletí de la Reial Acadèmia de Bones Lletres de Barcelona, 49 (2004), 249-316.

Reid, John T., "Notes on the Story of the Verso Esdrújulo», en Hispanic Review, VII (1939), 277-294.

Restrepo, Santiago y Ramón Valdés (eds.), Lope de Vega Carpio, El caballero del milagro, en Comedias de Lope de Vega. Parte XV, coord. Luis Sánchez Laílla, Madrid, Gredos, 2016, 2 vols., II, 971-1153.

Rico, Francisco (ed.), Miguel de Cervantes, Don Quijote de la Mancha, Barcelona, Galaxia Gutenberg, 2004, 2 vols.

Rojas Villandrando, Agustín de, El viaje entretenido, ed. Jacques Joset, Madrid, Espasa-Calpe, 1977, 2 vols.

Rueda, Lope de, El deleytoso, en Pasos, ed. de José Luis Canet Vallés, Madrid, Castalia, 1992, 108-167.

SÁnchez de Lima, Miguel, El arte poética en romance castellano, ed. Rafael de Balbín Lucas, Madrid, CSIC, 1944.

Sánchez Jiménez, Antonio, Lope pintado por sí mismo. Mito e imagen del autor en la poesía de Lope de Vega Carpio, Londres, Támesis, 2006.

—, «La batalla del romancero: Lope de Vega, los romances moriscos y La villana de Getafe», en Anuario Lope de Vega, 20 (2014), 159-186.

- (ed.), Lope de Vega Carpio, Romances de juventud, Madrid, Cátedra, 2015.

SÁnchez Lancis, Carlos, "La información lingüística diacrónica en la edición de la parte primera de las comedias de Lope de Vega», Anuario Lope de Vega, IV (1998), 311-326.

Serralta, Frédéric, "Sobre algunas rimas esdrújulas en Lope de Vega», en El placer de las formas en la literatura medieval y del Siglo de Oro, coord. Mó- 
nica Güell y Marie-Françoise Déodat-Kassedjian, Toulouse, Université de Toulouse-Le Mirail, 2008, 269-276.

Silvestri, Paolo, «Estilización tipológica y convencionalismo lingüístico en el teatro cómico de Giambattista Della Porta. La sátira de la erudición: el lenguaje del pedante», en Philologia Hispalensis, 7 (1992), 275-284.

Tubau, Xabi (ed.), Lope en 1604, Barcelona, Editorial Milenio, 2004, V-XIX.

Vega Carpio, Lope, Los comendadores de Córdoba, ed. José Enrique Laplana, en

Comedias de Lope de Vega. Parte II, coord. Silvia Iriso Ariz, Lérida, MilenioUniversitat Autònoma de Barcelona, 1998, 3 vols., II, 1023-1174.

-, El genovés liberal, ed. Elvezio Canonica-de Rochemonteix, en Comedias de Lope de Vega. Parte IV, coord. Luigi Giuliani y Ramón Valdés, Lérida, Milenio-Universitat Autònoma de Barcelona, 2002, 3 vols., II, 549-668.

—, El laurel de Apolo, ed. Antonio Carreño, Madrid, Cátedra, 2007.

—, El arrogante español o Caballero de milagro, versión de Guillermo Heras y Fernando Doménech, ed. Fernando Doménech, Madrid, RESAD-Editorial Fundamentos, 2007.

—, Los melindres de Belisa, ed. Jorge León, en Lope de Vega Carpio. Parte IX, coord. Marco Presotto, Lérida, Milenio-Universitat Autònoma de Barcelona, 2007, 3 vols, III, 1467-1600.

-, Los locos por el cielo, ed. Enric Bassegoda i Pineda, en Comedias de Lope de Vega. Parte VIII, coord. Rafael Ramos, Lérida, Milenio-Universitat Autònoma de Barcelona, 2009, 3 vols., III, 305-427.

—, La Dorotea, ed. Donald McGrady, Madrid, RAE, 2011.

-, La Arcadia, ed. de Ana María Porteiro Chouciño, en Comedias de Lope de Vega. Parte XIII, coord. Natalia Fernández Rodríguez, Madrid, Gredos, 2014, 2 vols., I, 47-230.

—, La francesilla, ed. Marta Latorre, en Comedias de Lope de Vega. Parte XIII, coord. Natalia Fernández Rodríguez, Madrid, Gredos, 2014, 2 vols. II, 569-752.

-, La viuda valenciana, ed. Rafael Ramos, en Comedias de Lope de Vega. Parte XIV, coord. José Enrique López Martínez, Madrid, Gredos, 2015, 2 vols., I, 833-997.

—, Romances de juventud, ed. Antonio Sánchez Jiménez, Madrid, Cátedra, 2015.

—, El caballero del milagro, eds. S. Restrepo y R. Valdés, en Comedias de Lope de Vega. Parte XV, coord. Luis Sánchez Laílla, Madrid, Gredos, 2016, 2 vols., II, 971-1153.

Zerolo, Elías, «Noticias de Cairasco de Figueroa y del empleo del verso esdrújulo en el siglo XVI», en Legajo de varios, París, Garnier Hermanos, Libreroseditores, 1897, 1-79. 
